\title{
Early swimming activity of hatchling flatback sea turtles Natator depressus: a test of the 'predation risk' hypothesis
}

\author{
Michael Salmon ${ }^{1, *}$, Mark Hamann ${ }^{2}$, Jeanette Wyneken ${ }^{1}$, Chloe Schauble ${ }^{3}$ \\ ${ }^{1}$ Department of Biological Sciences, Florida Atlantic University, Boca Raton, Florida 33426, USA \\ ${ }^{2}$ School of Earth and Environmental Sciences, James Cook University, Townsville 4811, Queensland, Australia \\ ${ }^{3}$ Burdekin Dry Tropics NRM, Townsville 4811, Queensland, Australia
}

\begin{abstract}
Marine turtle hatchlings emerge from nests on oceanic beaches, crawl to the surf zone and migrate offshore. Predators in shallow water can take many hatchlings, but once the turtles reach deeper water, both encounters with predators and mortality rates probably decline. Behavioral studies have demonstrated that hatchlings show changes in swimming activity as they migrate offshore. During the first $24 \mathrm{~h}$ of migration, most species swim continuously (the 'frenzy'), thereby minimizing their time in shallow waters; however, swimming activity later declines in duration and vigor, especially at night (the 'postfrenzy'). One interpretation of these differences is that hatchling migratory behavior evolved in response to the threat of predators (the 'predation risk' hypothesis). To further test this hypothesis, we quantified the daily swimming activity shown by the flatback Natator depressus, the only marine turtle that lacks an oceanic phase in its development. Instead, the hatchlings remain in relatively shallow Australian (continental shelf) waters where they may frequently encounter predators. We speculated that because of these encounters, flatback hatchlings might have evolved activity patterns that show little, if any, decline during migration. Over $4 \mathrm{~d}$ of laboratory observations, flatback activity at night declined by $\leq 13 \%$. Over the same time period, nocturnal activity declined by 60 to $95 \%$ (depending on species) in other marine turtles with an oceanic phase in their life history. Our data therefore support the hypothesis that predation played an important role in shaping the evolution of hatchling migratory behavior, although they do not provide direct evidence of a cause and effect relationship.
\end{abstract}

KEY WORDS: Flatback · Migration · Activity · Predators · Hatchling

Resale or republication not permitted without written consent of the publisher

\section{INTRODUCTION}

Marine turtles are large, long-lived reptiles that, as adults, are characterized by the fact that they have few enemies and high fecundity during many nesting episodes (Hendrickson 1980, Van Buskirk \& Crowder 1994, Heppell et al. 2003). The eggs, hatchlings and juvenile stages, however, typically endure high levels of mortality from an array of terrestrial, aquatic and aerial predators (Stancyk 1982, Wyneken 2000). Predation rates can be particularly severe during the earliest stages of migration (dispersal from the nest to offshore locations). Hatchlings generally crawl from the nest to the sea after surface sands cool, usually at night. Within minutes after they begin swimming, they are vulnerable to predators because they are easily detected in shallow water, are incapable of swimming faster than their predators, and have virtually no defense against an attack (Gyuris 1994, Stewart \& Wyneken 2004, Whelan \& Wyneken 2007).

Recent studies document that predation rates on hatchlings in shallow water vary with ecological conditions that determine the concentration of predators. Rates are lowest (average of $\sim 5 \%$; Stewart \& Wyneken 2004, Whelan \& Wyneken 2007) at sites where hatchlings swim across an open sand bottom because there 
are no refuges for predatory fishes from their own predators. Rates are highest (average of 30 to $50 \%$; Gyuris 1994, Pilcher et al. 2000) at sites where the turtles cross reefs with predaceous fishes of various species and sizes.

There is no evidence that females select nesting sites that are safer for either their eggs or their hatchlings. Instead, nesting females prefer remote sites that pose minimal risks of injury as they approach the beach to nest, or risks from predators that can take females while they nest (Mortimer 1995). Thus, hatchlings exiting any nesting beach usually face some degree of danger from predators. Their primary option may be to evolve behavioral strategies that reduce their chances of being detected. Two such hatchling strategies are known. One is to reduce the time available for detection by swimming vigorously and continuously offshore during a 'frenzy' period. This behavior is characteristic of green Chelonia mydas, loggerhead Caretta caretta and leatherback Dermochelys coriacea turtles departing from nesting beaches located in southeastern Florida, USA (Wyneken \& Salmon 1992). The frenzy lasts $\sim 24 \mathrm{~h}$ and is followed by a 'postfrenzy' period when the cost of locomotion is reduced by confining activity to the diurnal period (Wyneken \& Salmon 1992). By the time this transition occurs, the turtles are likely to be in deeper oceanic waters where encounters with predators are probably less frequent (Bolten 2003).

The second strategy is shown by hawksbill turtles Eretmochelys imbricata studied at the Turtle Islands off the coast of Borneo, Malaysia. These turtles show no frenzy period (Chung et al. 2009a). Rather, hatchlings swim in brief bouts for approximately the same amount of time $\left(\sim 6 \mathrm{~h} \mathrm{~d}^{-1}\right)$ over several days post-emergence. When not swimming, the turtles float inactively at the surface in a 'tuck' position, perhaps mimicking inanimate objects such as flotsam and other floating debris (Chung et al. 2009a). Dispersal away from the shallows is probably accomplished by drifting in tidal and wind-driven surface currents. Furthermore, swimming gaits used by the hatchlings gradually change over time. During the first $3 \mathrm{~d}$, the turtles swim primarily by using relatively inconspicuous, drag-based gaits such as 'dog paddling' and 'rear-flipper kicking' (Wyneken 1997). Beginning on Day 4, the turtles swim with increasing frequency by 'powerstroking', a faster and more conspicuous lift-based swimming gait (Chung et al. 2009b) that is also used by other species during the frenzy period (Wyneken 1997). By the time this transition occurs, the turtles have probably drifted well away from shallow coastal waters.

Thus, in all species studied to date, hatchlings show a change in behavior as they pass through dangerous and shallow coastal waters with many predators and enter into less dangerous, deeper offshore waters. The specific changes (from frenzy to postfrenzy activity; from drag- to lift-based swimming) obviously vary among species, but both phenomena are consistent with the hypothesis that hatchling behavior during dispersal has been shaped by selection in response to the probability of encountering predators (the 'predation risk' hypothesis). However, the evidence to date is based on correlation. Stronger support might come from observations on a hatchling marine turtle that experiences little or no change in encounter rates with predators during dispersal. Under these conditions, the hypothesis makes a specific prediction: when predation risk shows little change, hatchling turtles should show little or no temporal variation in their offshore swimming behavior.

The flatback Natator depressus is the only extant marine turtle that might fulfill this requirement. Hatchlings migrate offshore but do not depart from shelf waters surrounding the Australian mainland (Walker \& Parmenter 1990). Encounter rates with aquatic predators are unknown but since the turtles remain in relatively shallow ( $\leq 45 \mathrm{~m}$; Walker 1991) and productive coastal waters, rates should remain high. These elements of their biology prompted us to measure hatchling post-emergence swimming behavior over time (4 d). We found that activity levels did, indeed, remain high. The results are therefore consistent with the hypothesis that predation rates have shaped the evolution of hatchling behavior during offshore migration.

\section{MATERIALS AND METHODS}

Turtles. Hatchlings (4 to 6 from each of 4 nests) that were scheduled to emerge that night were collected from marked nests in the early evening at Mon Repos $\left(24^{\circ} 50^{\prime} \mathrm{S}, 152^{\circ} 25^{\prime} \mathrm{E}\right)$, or during the early afternoon from nests at Curtis Island $\left(23^{\circ} 35^{\prime} \mathrm{S}, 151^{\circ} 10^{\prime} \mathrm{E}\right)$, Queensland, Australia. Hatchlings were placed in covered, sand-filled buckets and transported within minutes (Mon Repos clutches) or several hours (Curtis Island clutches) to our laboratory at Bargara where they were stored in a covered cooler with moist sand. A few minutes before midnight, the turtles were weighed (nearest $0.01 \mathrm{~g}$ ) using an electronic scale and measured (straight carapace length, SCL) using calipers (nearest $0.1 \mathrm{~mm}$ ).

Activity measurements. At midnight, each turtle was placed inside a circular tank $(110 \mathrm{~cm}$ diameter $)$ that was filled with seawater to a depth of $40 \mathrm{~cm}$ (Fig. 1). A turtle's swimming activity was recorded by placing the individual inside a nylon-lycra harness that was attached by a short length of a tether (monofilament) line to a horizontal tracker arm (wooden dowel) posi- 

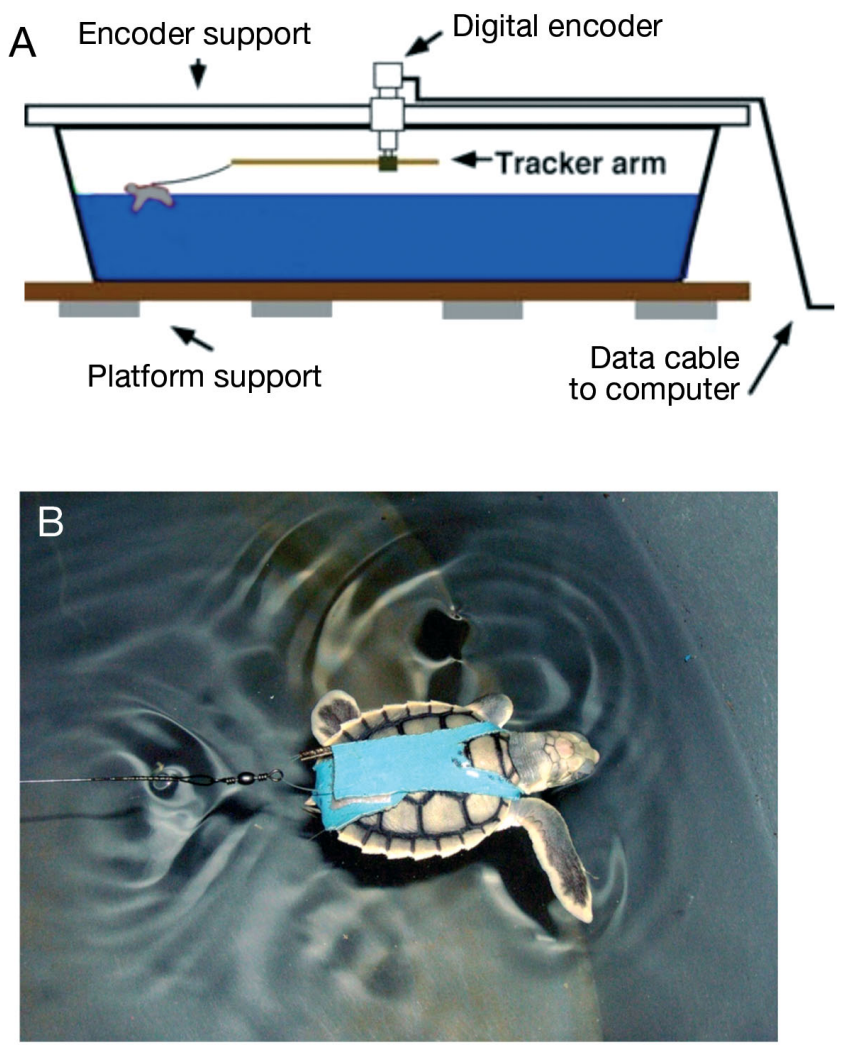

Fig. 1. (A) Side view of the tank and recording system used to measure hatchling swimming activity. While swimming, the hatchling is tethered to a tracker arm that rotates in the horizontal plane from its central location above water level. The force of the turtle's swimming effort pulls the arm slightly downward, closing a circuit that measures active time. This information is conveyed by a digital encoder to a computer, where it is stored. (B) A tethered flatback Natator depressus in its nylon-lycra harness

tioned just above the water surface (Fig. 1). The arm rotated freely in the horizontal plane. Turtles could swim in any direction and make shallow dives, but the tether length was adjusted so that hatchlings could not touch the tank sides or bottom (Wyneken \& Salmon 1992). The tracker arm also pivoted a few degrees in the vertical plane. When the turtle swam, the arm was pulled downward to complete a 'turtle active' circuit to a digital encoder; when the turtle was inactive, a counter-weight at the opposite end returned the arm to a horizontal position, breaking the circuit. A computer program (Arena Tracker; W. Irwin, University of North Carolina) monitored arm position at $10 \mathrm{~s}$ intervals and sent the data from the encoder to a computer where it was stored for the duration of observations (96 h). System integrity was checked twice daily to ensure that activity was recorded accurately. After the observations were completed, the harnesses were removed and the turtles were taken offshore and released.
Our laboratory was a non-airconditioned enclosed garage with a southeast facing window that exposed the turtles to ambient shaded temperatures and indirect diffuse natural lighting. There was sufficient space to house 6 tanks. Seawater temperatures ranged between 26.0 and $28.5^{\circ} \mathrm{C}$ and were within the range of daily average sea surface temperatures for the Bargara coast during the study period $\left(26.0\right.$ to $29.0^{\circ} \mathrm{C}$ ). Room lighting was supplemented by 4 ceiling-mounted broad-spectrum fluorescent tubes, which were turned on $\sim 30$ min after sunrise and off $\sim 30$ min before sunset.

Data analysis and statistics. Data were exported to Excel and summarized by active time during each diel $(24 \mathrm{~h})$ period, and during the diurnal and nocturnal portions of each day. Data were converted to proportions of active time during these periods and then arcsine square root-transformed to promote normality. Transformed proportions among periods were compared to one another using repeated-measures ANOVA. When differences were found, the days responsible were identified using Tukey-Kramer comparisons (Zar 1999) at a significance level of 0.01 .

\section{RESULTS}

Activity records were obtained for 21 hatchlings from 4 nests (4 to 6 hatchlings nest ${ }^{-1}$ ). Three nests came from Mon Repos and one nest came from Curtis Island. The turtles ranged in mass between 33.5 and $49.2 \mathrm{~g}$ (mean \pm SD: $40.4 \pm 5.61 \mathrm{~g}$ ) and in SCL between 57.0 and $69.5 \mathrm{~mm}(62.2 \pm 4.25 \mathrm{~mm})$.

Turtles were active for $98,96.5,93.7$ and $94 \%$ of diel periods 1 to 4 , respectively (Fig. 2). Differences among diel periods were statistically significant (ANOVA of the arcsin-transformed data; $F=11.79, \mathrm{p}_{3,20} \leq 0.0001$ ). Post-hoc Tukey tests showed that activity during diel period 1 exceeded that during diel periods 3 and 4, and activity during diel period 2 exceeded that during diel period 3 but not diel period 4 (Fig. 2).

Diurnal activity varied by $\leq 3 \%$ across days (Fig. 3, left) and did not differ significantly over the $4 \mathrm{~d}$ of measurement (ANOVA $F=2.81, \mathrm{p}_{3,20}=0.047$ ). Nocturnal activity declined by as much as $13 \%$ across nights, with the greatest difference being that between Nights 1 and 3 (Fig. 3, right). Differences among nights were statistically significant (ANOVA of arcsin transformed proportions; $\left.F=23.75, \mathrm{p}_{3,20} \leq 0.0001\right)$. The turtles were more active during Night 1 than during all other evenings, and were more active during Night 2 than during Nights 3 and 4 (post-hoc Tukey tests, Fig. 3).

When the turtles were swimming beneath the surface, they did so by powerstroking; dogpaddling or rear-flipper kicking was used when the turtles came to the surface to breathe. During the third and fourth day 


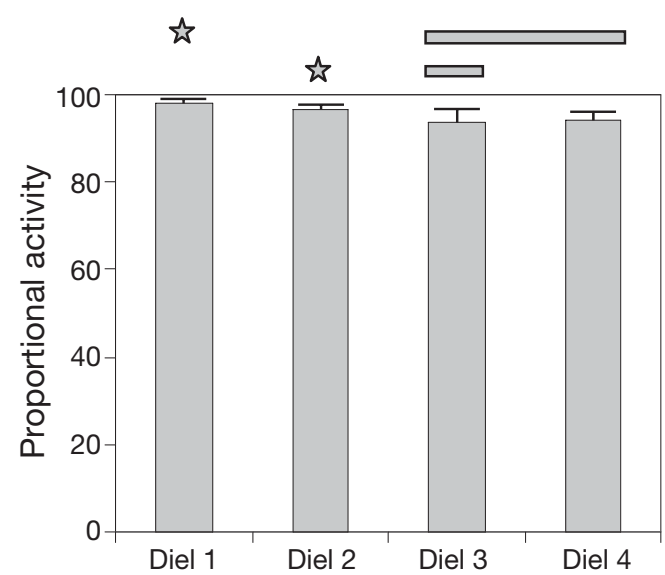

Fig. 2. Natator depressus. Proportion of time (mean $\% \pm \mathrm{SE}$ ) when flatback hatchlings $(\mathrm{n}=21)$ actively swam over each $24 \mathrm{~h}$ (diel) period during the $4 \mathrm{~d}$ of observations. (级) Days when activity exceeded that during the following days below the horizontal bar (as determined by post-hoc Tukey tests)

of recordings, we attempted to feed the turtles with small pieces of raw shrimp but none accepted the food.

\section{DISCUSSION}

\section{Some questions answered but many others remain}

During observations, flatback hatchlings showed modest but statistically significant changes in activity over time, with a tendency for activity to decline (Fig. 2). This decline was striking in 2 respects: its consistency among the hatchlings from all nests, and its small magnitude $(<5 \%$; Fig. 2) compared to that in other species of marine turtles. The greatest change was in nocturnal activity (Fig. 3), but even during this period, flatbacks swam for most $(\geq 87 \%)$ of the dark period. In other species, the decline in nocturnal activity by the end of the fourth evening ranged between $\sim 60 \%$ in leatherbacks to $\sim 80 \%$ in green turtles and $\sim 95 \%$ in loggerheads from southeastern Florida (Wyneken \& Salmon 1992). Thus, the reduction in flatback swimming activity during offshore dispersal is proportionally smaller than in species that include both a frenzy period and an oceanic phase in their development. These results are thus consistent with the hypothesis that predation pressures have been an important (although not necessarily the only) factor shaping offshore migratory behavior in flatbacks, as well as in other species of marine turtles over their long history (Gyuris 2004).

Recent studies indicate significant correlations between ecology and offshore migratory activity even within species with an oceanic phase. For example, Malaysian green turtles show a frenzy period that is about twice as long (Chung et al. 2009a) as the frenzy period shown by Florida green turtles (Wyneken \& Salmon 1992). Loggerhead hatchlings departing from the southwest coast of Florida are significantly more active during offshore migration than hatchlings departing from similar latitudes on the southeast coast (Wyneken et al. 2009). In both examples, the more active turtles are hypothesized to encounter a greater abundance of predators (either over time, through space, or both) before they reach the relative safety of deep water.

Our results raise many questions that can only be answered when flatback ecology and behavior during ontogeny have been further studied. For example, how can the turtles maintain high levels of activity? For how long during development does almost continuous activity persist? Are specific locations within the continental shelf more favorable for the growth and survival
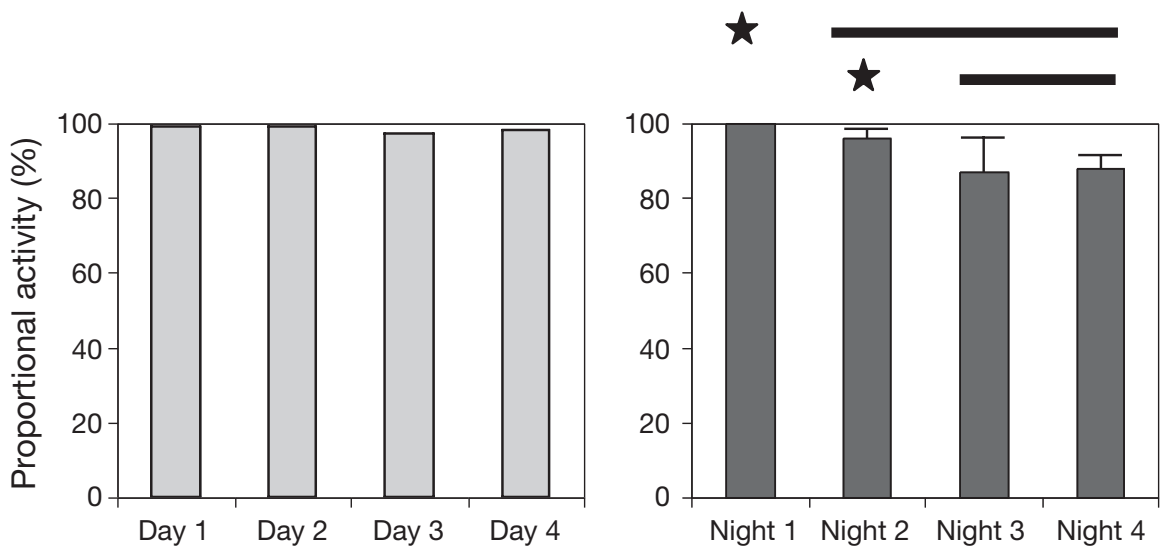

Fig. 3. Natator depressus. Proportion of the diurnal (left, days) and nocturnal (right, nights) periods (mean $\% \pm$ SE) when flatback hatchlings $(\mathrm{n}=21)$ actively swam during the $4 \mathrm{~d}$ of observations. $(\star)$ Nights when activity exceeded that during the following nights below the horizontal bar (as determined by post-hoc Tukey tests) 
of neonate turtles than of other life stages, i.e. do the hatchlings simply migrate to any location on the continental shelf or do they (like loggerheads; Bolten 2003) have broad regional 'goals'? At what size and age do the turtles shift from feeding in the water column to benthic feeding (Limpus 2007)? The answers to these questions will advance our understanding not only of flatback biology, but also of the pathways of evolutionary divergence among marine turtle species.

\section{How flatbacks might avoid their predators}

We hypothesize in this study that because flatbacks remain in coastal waters, they should encounter predators more frequently and therefore must remain active during both day and night. Known predators are both aerial during the day (sea eagles Haliaeetus leucogaster; Walker \& Parmenter 1990) and aquatic during the day and at night (crocodiles, sharks and teleosts; Limpus 2007).

Flatbacks probably have options for either avoiding or minimizing predation risk, although none of these options has been studied to date. The following are some possibilities. The grey carapace coloration of both hatchling and neonate turtles makes them difficult for a human observer to see from above in turbid coastal waters, even when the turtles are swimming less than $1 \mathrm{~m}$ below the surface. This crypticity might also apply to their detection by other predators. The turtles are known to remain in relatively shallow coastal waters (Walker 1991) that are typically both productive and turbid (see maps in Limpus 2007). Neonates are also countershaded (white plastron; Limpus 2007), which probably makes them more difficult for predaceous fishes to detect from either above, the side, or below.

Flatback hatchlings by virtue of their size are thought to contain more energy (yolk) stores and to be more powerful swimmers (Walker \& Parmenter 1990) than the smaller hatchlings of other hard-shelled marine turtles. A larger yolk supply may enable the turtles to reduce the probability of death by starvation. This might explain why turtles confined to pools showed no interest in feeding over $4 \mathrm{~d}$, whereas loggerhead and green turtle hatchlings under the same conditions usually accept food within $3 \mathrm{~d}$. An ability to swim powerfully and rapidly may enable flatback hatchlings to avoid predators by outmaneuvering them, escaping into murky areas or into muddy substrates, or even by fighting back. By virtue of their size, newly emerged flatbacks can escape from many terrestrial predators (Limpus 1971); they can probably also avoid capture by carnivorous fishes whose gape limits the size of prey that they can consume (Abra- hams 2006). Larger-than-average size has been shown to significantly improve the survival of dispersing green turtle (Gyuris 2004) and red ear slider Trachemys scripta elegans (Janzen et al. 2000) hatchlings, but not of hatchlings of other turtle species (e.g. gopher tortoises Gopherus polyphemus and snapping turtles, Chelydra serpentina; Congdon et al. 1999, Pike \& Seigel 2007).

Adult flatbacks possess blood haemoglobins with a greater affinity for oxygen at high partial pressures than the haemoglobins of loggerheads and, most likely, green turtles (Sperling et al. 2007). Assuming that flatback hatchlings have similar blood chemistry to adults, 2 advantages should be evident. First, hatchlings should be able to more rapidly replenish their oxygen stores and thus minimize their exposure time at the surface where all air-breathing animals that dive are most vulnerable to predators (Heithaus \& Frid 2003). Second, the $\mathrm{O}_{2}$ dissociation characteristics should result in a more prolonged release of oxygen during each dive (Sperling et al. 2007), maximizing the time available underwater for foraging. This is important because rapidly outgrowing predators is a prerequisite for the survival of young marine turtles (Hendrickson 1980, Van Buskirk \& Crowder 1994). Modifications to diving behavior that promote predator avoidance and improve the efficiency of feeding may contribute importantly to the achievement of these goals.

Flatbacks also show striking differences in their life history characteristics from their hard-shelled marine turtle relatives. These differences provide supporting evidence that young flatbacks avoid predators more effectively than the younger life history stages of other marine turtle species. Flatbacks produce clutches that are approximately half the size of those of other marine turtles, but their eggs are larger and develop into hatchlings that are almost twice the mass of those of the other Cheloniidae (Walker \& Parmenter 1990, Van Buskirk \& Crowder 1994). Flatbacks do not compensate for reduced fecundity either by nesting more often during each breeding season or by decreasing the interval between successive breeding seasons (van Buskirk \& Crowder 1994). Based on life-history theory, if populations are numerically stable, then juvenile survival must be proportionally higher in flatbacks than in marine turtles that produce more eggs and offspring (Walker \& Parmenter 1990). Estimates based on female fecundity, breeding intervals, hatchling emergence probabilities, rates of female recruitment, and measurements of female longevity are consistent with this hypothesis (Parmenter \& Limpus 1995). What is especially interesting is that these results apply even though flatbacks remain in shallow continental shelf waters (where they are presumably confronted with 
high concentrations of predators) during their most vulnerable life history stages.

In this study, we describe another strategy in a suite of behavioral strategies employed by hatchling marine turtles that might promote survival during dispersal from the nesting beach. These include the capacity to (1) swim continuously and rapidly offshore, thereby minimizing their exposure time in shallow water (frenzy period of green turtles, loggerheads, and leatherbacks; Wyneken \& Salmon 1992, Chung et al. 2009a, Wyneken et al. 2009), (2) deprive predators of movement cues and, perhaps, deceive them by mimicking flotsam (hawksbills; Chung et al. 2009a,b), or (3) remain continuously active to increase their probability of avoiding predators and/or finding food (flatbacks). These strategies may be viewed as working hypotheses that need testing to determine whether they actually promote survival compared to other behavioral alternatives (i.e. whether they constitute 'adaptations'; Reeve \& Sherman 1993). Such studies will require carefully designed experiments and field observations. Unfortunately, these data will not be easily obtained using flatbacks as subjects because these turtles are found in turbid waters where they are difficult to observe, and because they share these habitats with predators (crocodiles and sharks) that constitute threats not only to the turtles, but also to the naturalists who study them.

Acknowledgements. This project was funded through a grant from the Seaworld Research and Rescue Foundation. Additional support was provided by the Florida Atlantic University and by generous contributors to the Nelligan Sea Turtle Fund. Assistance in the field was provided by C. and D. Limpus of Queensland Parks and Wildlife Service (QPWS), and by J. and P. Barrett from Curtis Island. The project was authorized by a QPWS science permit (WITK01589103) and a University of Queensland animal ethics permit (No. ANATDB/593/03/ SWRR).

\section{LITERATURE CITED}

Abrahams M (2006) The physiology of antipredator behaviour: what you do with what you've got. In: Sloman KA, Wilson RW, Balshine S (eds) Behaviour and physiology of fish. Elsevier Academic Press, London, p 79-109

Bolten AB (2003) Variation in sea turtle life history patterns: neritic vs. oceanic developmental stages. In: Lutz PL, Musick JA, Wyneken J (eds) The biology of sea turtles. CRC Press, Boca Raton, FL, p 243-257

Chung CF, Pilcher NJ, Salmon M, Wyneken J (2009a) Offshore migratory activity of hawksbill (Eretmochelys imbricata L) hatchlings. I. Quantitative analysis of activity, with comparisons to green turtles (Chelonia mydas L). Chelonian Conserv Biol 8:28-34

> Chung CF, Pilcher NJ, Salmon M, Wyneken J (2009b) Offshore migratory activity of hawksbill (Eretmochelys imbricata L) hatchlings. II. Swimming gaits, swimming speed, and morphological comparisons. Chelonian Conserv Biol 8:35-42
Congdon JD, Nagle RD, Dunham AE, Beck CW, Kinney OM, Yeomans SR (1999) The relationship of body size to longevity of hatchling snapping turtles (Chelydra serpentina): an evaluation of the 'bigger is better' hypothesis. Oecologia 121:224-235

Gyuris E (1994) The rate of predation by fishes on hatchlings of the green turtle (Chelonia mydas). Coral Reefs 13: $137-144$

Gyuris E (2004) The relationship between body size and predation rates on hatchlings of the green turtle (Chelonia mydas): Is bigger better? In: Pilcher NJ, Ali L (eds) Sea turtles of the Indo-Pacific. ASEAN Academic Press, London, p 143-147

> Heithaus MR, Frid A (2003) Optimal diving under the risk of predation. J Theor Biol 223:79-92

Hendrickson JR (1980) The ecological strategies of sea turtles. Am Zool 20:597-608

Heppell SS, Crowder LB, Crouse DT, Epperly SP, Frazer NB (2003) Population models for Atlantic loggerheads: past, present, and future. In: Bolten $\mathrm{AB}$, Witherington $\mathrm{BE}$ (eds) Loggerhead sea turtles. Smithsonian Books, Washington, DC, p 255-273

> Janzen FJ, Tucker JK, Paukstis GL (2000) Experimental analysis of an early life-history stage: avian predation selects for larger body size of hatchling turtles. J Evol Biol 13:947-954

Limpus CJ (1971) The flatback turtle, Chelonia depressa Garman, in Southeast Queensland, Australia. Herpetologica $27: 431-446$

Limpus CJ (2007) A biological review of Australian marine turtle species. 5. Flatback turtle, Natator depressus Garman. Queensland Environmental Protection Agency, Brisbane

Mortimer JA (1995) Factors influencing beach selection by nesting sea turtles. In: Bjorndal KA (ed) Biology and conservation of sea turtles. Smithsonian Institution Press, Washington, DC, p 45-52

Parmenter CJ, Limpus CJ (1995) Female recruitment, reproductive longevity and inferred hatchling survivorship for the flatback turtle (Natator depressus) at a major eastern Australian rookery. Copeia 474-477

Pike DA, Seigel RA (2007) Is longevity related to body size or behavior in a hatchling turtle? Russ J Herpetol 14:81-86

Pilcher NJ, Enderby S, Stringell T, Batemen L (2000) Nearshore turtle hatchling distribution and predation. In: Pilcher NJ, Ali L (eds) Sea turtles of the Indo-Pacific. ASEAN Academic Press, London, p 151-166

> Reeve HK, Sherman PW (1993) Adaptation and the goals of evolutionary research. Q Rev Biol 68:1-32

Sperling JB, Grigg GC, Beard LA, Limpus CJ (2007) Respiratory properties of blood in flatback turtles (Natator depressus). J Comp Physiol B 177:779-786

Stancyk SE 1982. Non-human predators of sea turtles and their control. In: Bjorndal KA (ed) Biology and conservation of sea turtles. Smithsonian Institution, Washington, DC, $\mathrm{p}$ 19-38

Stewart KR, Wyneken J (2004) Predator risk to loggerhead hatchlings at a high-density nesting beach in southeast Florida. Bull Mar Sci 74:325-335

Van Buskirk J, Crowder LB (1994) Life-history variation in marine turtles. Copeia 1994:66-81

> Walker TA (1991) Juvenile flatback turtles in proximity to coastal nesting islands in the Great Barrier Reef Province. J Herpetol 25:246-248

Walker TA, Parmenter CJ (1990) Absence of a pelagic phase in the life cycle of the flatback turtle, Natator depressa (Garman). J Biogeogr 17:275-278 
Whelan C, Wyneken J (2007) Estimating predation levels and site-specific survival of hatchling loggerhead sea turtles (Caretta caretta) from South Florida beaches. Copeia 2007:745-754

Wyneken J (1997) Sea turtle locomotion. In: Lutz PL, Musick JA (eds) The biology of sea turtles. CRC Press, Boca Raton, FL, p 155-198

Wyneken J (2000) The migratory behavior of hatchling sea turtles beyond the beach. In: Pilcher NJ, Ismail G (eds) Sea turtles of the Indo-Pacific. ASEAN Academic Press,

Editorial responsibility: Mathew Godfrey,

Beaufort, North Carolina, USA
London, p 121-142

Wyneken J, Salmon M (1992) Frenzy and postfrenzy swimming activity in loggerhead, leatherback, and green sea turtles. Copeia 1992:478-484

Wyneken J, Madrak SV, Salmon M, Foote J (2009) Migratory activity by hatchling loggerhead sea turtles (Caretta caretta L): evidence for population divergence. Mar Biol 156:171-178

Zar JH (1999) Biostatistical analysis. Prentice Hall, Englewood Cliffs, NJ

Submitted: March 25, 2009; Accepted: August 29, 2009

Proofs received from author(s): November 9, 2009 